\title{
POTENCIAL TRANSFORMADOR DA GESTAÇÃO E DO PARTO NA VIDA DAS MULHERES: EVIDÊNCIAS QUALITATIVAS
}

\section{TRANSFORMATIVE POTENTIAL OF PREGNANCY AND CHILDBIRTH IN WOMEN'S LIFE: QUALITATIVE EVIDENCES}

\section{POTENCIAL TRANSFORMADOR DEL EMBARAZO Y DEL PARTO EN LA VIDA DE MUJERES: EVIDENCIAS CUALITATIVAS}

\author{
Zayonaria Magalhães Mendonça Mota ${ }^{1}$ \\ Saiwori de Jesus Silva Bezerra dos Anjos \\ Alisson Salatiek Ferreira de Freitas ${ }^{3}$ \\ Antonio Rodrigues Ferreira Júnior ${ }^{4}$
}

Como citar este artigo: Mota ZMM, Anjos SJSB, Freitas ASF, Ferreira Júnior AR. Potencial transformador da gestação e do parto na vida das mulheres: evidências qualitativas. Rev baiana enferm. 2019;33:e28286.

\begin{abstract}
Objetivo: identificar o potencial transformador da gestação e do parto na vida das mulheres e dos familiares por meio de evidências qualitativas. Método: revisão da literatura e construção de uma metassíntese, no período de agosto de 2017 a janeiro de 2018. Foi utilizada a estratégia PICO para elaboração da pergunta de pesquisa. A busca foi realizada na Biblioteca Virtual em Saúde, mediante a associação entre os descritores "Acontecimentos que mudam a vida", "Gestação" e "Parto". A amostra final foi constituída de 21 publicações. Resultados: três categorias temáticas emergiram dos dados e geraram discussões acerca dos campos temáticos gestação, ponto de transformação, influência do meio e parto como portal. Conclusão: o impacto da gestação desencadeia um potencial transformador intrínseco e possibilita modificações em vários âmbitos da vida da mulher e da família, podendo ser ampliadas pela influência do meio.
\end{abstract}

Descritores: Acontecimentos que Mudam a Vida. Gravidez. Parto. Prática Baseada em Evidência. Enfermagem.

Objective: to identify the transformative potential of pregnancy and childbirth in the lives of women and their families through qualitative evidences. Method: literature review and construction of a meta-synthesis, from August 2017 to January 2018. The PICO strategy was used to elaborate the research question. The search was performed at the Virtual Health Library, by associating the following descriptors: "Life-changing events", "Pregnancy" and "Childbirth". The final sample consisted of 21 publications. Results: Three thematic categories emerged from the data and generated discussions about the following thematic fields: pregnancy, transformation point, influence of the environment and

\footnotetext{
Enfermeira. Universidade Estadual do Ceará. Fortaleza, Ceará, Brasil.

Enfermeira. Doutora em Enfermagem. Professora Adjunta da Universidade Estadual do Ceará. Fortaleza, Ceará, Brasil. saiwori.anjos@uece.br

Enfermeiro. Mestre em Ensino na Saúde. Professor do Centro Universitário Christus. Fortaleza, Ceará, Brasil.

Enfermeiro. Doutor em Enfermagem. Professor Adjunto da Universidade Estadual do Ceará. Fortaleza, Ceará, Brasil.
} 
childbirth as a portal. Conclusion: the impact of pregnancy unleashes an intrinsic transformative potential and enables changes in various spheres of women's and family life, which can be magnified by the influence of the environment.

Keywords: Life-changing Events. Pregnancy. Childbirth. Evidence-based Practice Nursing.

Objetivo: identificar el potencial transformador del embarazo y del parto en la vida de mujeres y familiares por medio de evidencias cualitativas. Método: revisión de la literatura y elaboración de una metasintesis, durante el período de agosto de 2017 a enero de 2018. Se utilizó la estrategia PICO para elaborar la pregunta de la investigación. La búsqueda se realizó en la Biblioteca Virtual de Salud mediante una asociación entre los siguientes descriptores: "Acontecimientos que cambian la vida", "Embarazo" y "Parto". La muestra final estuvo conformada por 21 publicaciones. Resultados: de los datos emergieron tres categorias temáticas y generaron debates acerca de los siguientes campos temáticos: embarazo, punto de transformación, influencia del medio y el parto como un portal. Conclusión: el impacto del embarazo desencadena un potencial transformador intrínseco y permite modificarvarios ámbitos de la vida de la mujer y de la familia, pudiendo ser ampliadas por la influencia del medio.

Descriptores: Acontecimientos que Cambian la vida. Embarazo. Parto. Práctica Basada en Evidencias. Enfermería.

\section{Introdução}

O ser humano, espécie em constante processo de autoconhecimento e desenvolvimento pessoal, está na dependência direta dos tipos de estímulo que recebe no meio em que vive. Em sua construção pessoal, assim como as famílias, passam por processos-chave das mais variadas tipificações durante suas vidas ${ }^{(1)}$. Configurados nas crises imediatas ou nas adaptações de longo prazo, quando experienciados de forma resiliente, não deixando a busca por sentido ser esquecida, esses processos produzem pessoas e relações mais íntimas e fortes.

A gestação pode ser considerada um evento-chave que desencadeia o processo de resiliência. Ao visar a nova configuração, necessária para assumir o papel social que se apresenta, mostra-se como uma oportunidade para o crescimento pessoal e o autoconhecimento ${ }^{(2)}$. Assim, as transformações físicas e emocionais geradas pela gestação favorecem, nas mulheres, a percepção de que já não são as mesmas, de que agora seu corpo e sua função no mundo mudaram. Pode-se entender esse momento como um dos principais da maternidade ${ }^{(3)}$. Assim, a gestação e sua culminância, o parto, configura-se como um processo indissociável que exerce papel relevante na família.

O parto, por sua vez, não sendo um acontecimento neutro, implica vivenciar um conjunto complexo de sentimentos, que não se restringem ao acontecimento em si, mas também engloba as expectativas sobre a vivência prévia ao parto e puerpério ${ }^{(4)}$. Vale ressaltar que, muitas vezes, as transformações da gestação e do parto são abordadas de forma separada. Contudo, elas são indissociáveis, por se tratar de um contínuo com crescente impacto e diferentes níveis de percepção.

Não se poderia pensar a gestação como um mero período de preparação para a maternidade e o nascimento apenas como o marco efetivo do seu exercício propriamente dito. Tratar-se-ia, sim, de entender o período gestacional como uma importante etapa da constituição da maternidade, na qual se estabelece um exercício cada vez mais ativo do papel materno, cujo ápice se dará após o nascimento do bebê. O bebê já existe na fala das gestantes e evoca sentimentos e mudanças específicas e diretamente relacionadas a ele. Nesse contexto, a maternidade não é futura, é presente ${ }^{(3)}$. Desse modo, o parto assume a simbologia de portal, pontuando o marco inicial das novas configurações existenciais, minunciosamente tecidas durante os nove meses da gestação.

É comum a classificação de tais eventos-chave como neutros, positivos ou negativos, não havendo um aprofundamento no campo 
da singularidade de cada um deles. No entanto, alguns casos, como o nascimento de uma criança, por exemplo, não se enquadram em uma definição rígida, trazendo desde maior negatividade no que diz respeito a sua avaliação cognitiva como também crescente satisfação no campo emocional $^{(5)}$.

As ações em saúde materna, quando mantém um modelo de atenção que não abrange os fatores psicossociais de forma favorável, por costumeiramente privilegiar a dimensão biológica, deixam escapar um aspecto primordial para o cuidado integral do ser ${ }^{(6)}$. Tal modelo de atenção configura-se fator d e fragilidade e insegurança materna e familiar. Isso, em conjunto com fatores relacionados à ambiência e ao preparo profissional deficientes, à não criação de vínculo profissional/família, assim como à orientação inadequada durante o pré-natal e falhas estruturais de instituições e sistemas de saúde, pode gerar uma experiência negativa em relação ao parto ${ }^{(7)}$.

Nesse contexto, as práticas educativas possuem forte papel na promoção do protagonismo materno e familiar, encontrando como impasse a disparidade existente entre as recomendações normativas e as realidades institucionais. Isso pode desencadear na mulher efeito inverso no que diz respeito ao reconhecimento de seus direitos e à impossibilidade de exercê-los ${ }^{(8)}$.

Percebe-se que existe uma lacuna com relação à percepção da maternidade como ação transformadora. Baseado nessa perspectiva, o estudo justifica-se pelo fato de buscar compreender a complexidade desse acontecimento que permeia o campo biopsicossocial, cultural, espiritual, sexual e familiar, trazendo resultados que propiciem um entendimento ampliado do profissional da saúde acerca do processo transformador do gestar e parir. Tais constatações possibilitaram o surgimento do seguinte questionamento norteador: Quais transformações ocorreram na vida das mulheres durante a gestação e o parto?

O estudo, ao estabelecer a relação do processo de gestação e parto com a construção da maternidade e reformulação da identidade pessoal dos indivíduos envolvidos, pretende (re)significar tal processo, subsidiando $\mathrm{O} \mathrm{CO}^{-}$ nhecimento dos profissionais sobre o evento de gestação e parto. Tal ação pode favorecer a superação da carência de conhecimento sobre esse processo, o que oportuniza também às mulheres uma vivência ampliada e reflexiva dessa fase da vida.

Com isso, objetivou-se identificar o potencial transformador da gestação e do parto na vida das mulheres e familiares por meio de evidências qualitativas.

\section{Método}

Trata-se de uma metassíntese com evidências qualitativas. Sua realização é norteada por parâmetros metodológicos rigorosos, sistemáticos e objetivos que devem conduzir a análise crítica da produção científica, utilizando material já publicado para disponibilizar um conhecimento amplo de cunho interpretativo ${ }^{(9)}$.

Para desenvolvimento da pergunta problema desta pesquisa, utilizou-se do método PICO, acróstico referente à população estudada, ao interesse e ao contexto. Desta forma, tem-se P: mulheres que se tornaram mães; I: houve transformação pessoal/mudança na vida; Co: gestação e parto. Pergunta de partida: Quais transformações ocorreram na vida das mulheres durante a gestação e o parto?

A busca deu-se entre os meses de agosto de 2017 e janeiro de 2018. O levantamento foi realizado no banco de dados Biblioteca Virtual em Saúde (BVS), sem restrições para o ano de publicação ou utilização de filtros. Para abordar todo o conteúdo já publicado acerca da temática, utilizou-se o descritor "Acontecimentos que Mudam a Vida" em associação aos descritores "Gravidez" e "Parto".

Com isso, em uma busca exploratória, foram encontrados 1.017 artigos na associação das categorias F01.829.458.410 and G08.686.784.769.490 respectivamente "Acontecimentos que Mudam a Vida" and "Gravidez"; e entre F01.829.458.410 and G08.686.784.769, relativo a "Acontecimentos que Mudam a Vida" and "Parto", obteve-se 78 artigos. Desse modo, foi encontrado um total de 
1.095 artigos. Foram excluídos artigos que tratavam, em seu título, de temáticas com foco do estudo em outro evento-chave em associação a gestação, não representando o interesse desta pesquisa. Esses estudos tratavam de puerpério e estresse pós-traumático, violência obstétrica, comorbidades associadas, aborto, depressão, paternidade, desenvolvimento infantil, pesquisas quantitativas e revisões sistemáticas. Dentre esses, o maior número de publicação estava voltado para depressão pós-parto em suas mais variadas vertentes.
Selecionados quanto ao título para leitura de resumo, restaram 95 artigos entre ambas as associações de descritores. Dentre esses, restaram 47 que não possuíam nenhum dos critérios de exclusão supracitados e/ou por não deixarem claro, no resumo, o objetivo da pesquisa e/ou sua metodologia, tornando-se necessária a leitura na íntegra. Após ter acesso aos textos na íntegra, seguiu-se para a leitura de 28 artigos, restando, destes, 21 que compuseram amostra total do estudo (Figura 1).

Figura 1 - Fluxograma metodológico de identificação e seleção dos estudos para a metassíntese

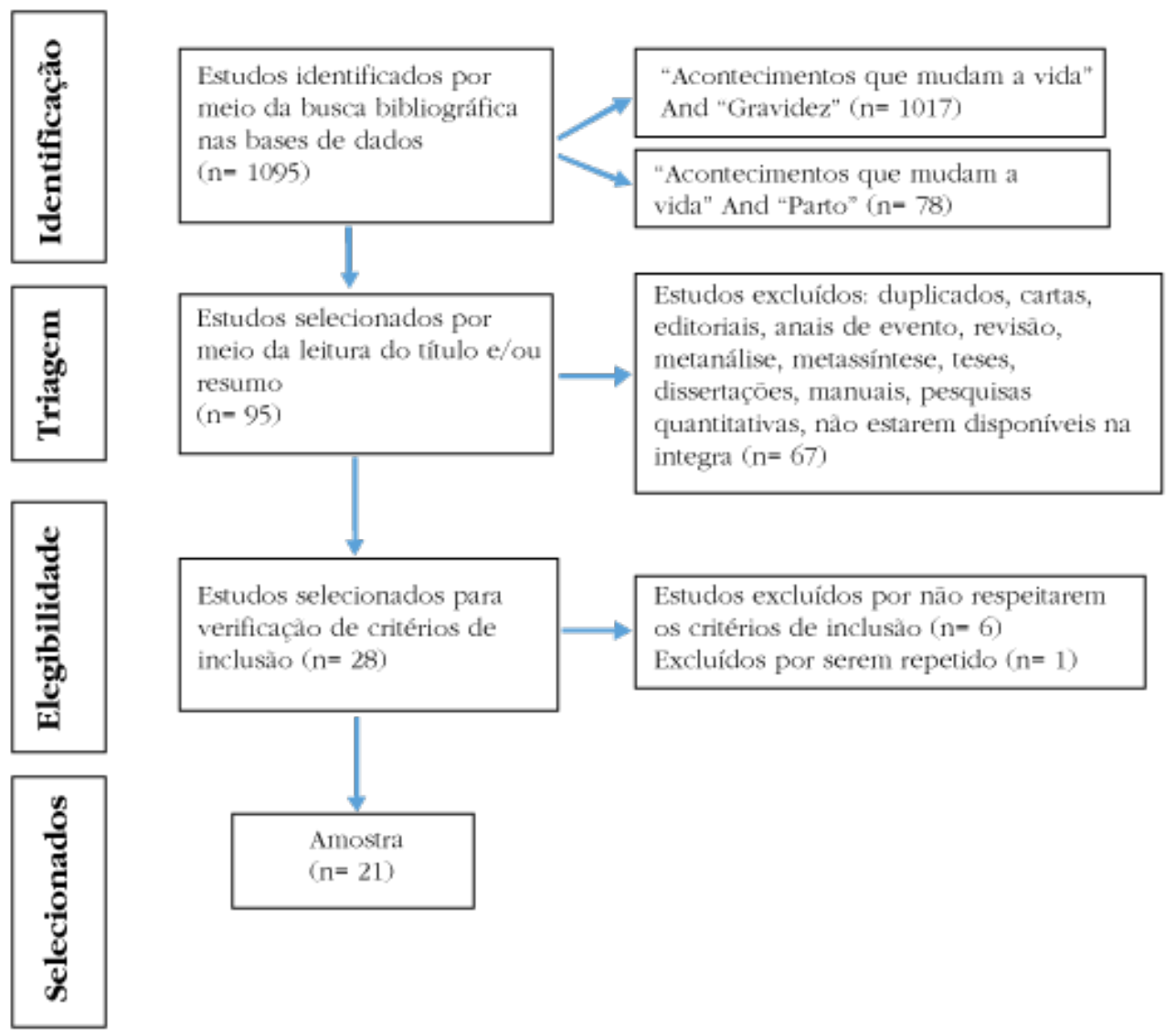

Fonte: Elaboração própria.

Definido o material, os estudos foram apreciados por meio da análise de conteúdo temática, seguindo três fases: pré-análise, exploração do material e interpretação dos dados. A análise e o agrupamento de ideias deram surgimento a três categorias: gestação, ponto de transformação; influência do meio em que vivem; parto como transição.

\section{Resultados e Discussão}

O corpo da análise, para compor essa metassíntese, contou com 21 artigos, que foram lidos na íntegra e avaliados quanto à sua capacidade de responder à pergunta do estudo. Eles estão expostos com detalhamento no Quadro 1, 
o qual apresenta informações sobre título, ano de publicação, local da pesquisa, população participante, objetivos. Do total de artigos, seis foram publicadas em português, realizados no Brasil, datados entre 1995 e 2017, e quinze em inglês, realizados entre 2004 e 2017 , respectivamente na Austrália, África do Sul, Nova Zelândia, Irlanda, Inglaterra, Bélgica, Armênia e Tailândia, Gâmbia, Suécia.

Quadro 1 - Caracterização dos estudos sobre o potencial transformador do gestar e parir analisados

(continua)

\begin{tabular}{|c|c|c|c|}
\hline $\begin{array}{l}\mathbf{N}^{\circ} \\
\text { referência }\end{array}$ & Ano, local & Título & Objetivos \\
\hline 3 & $\begin{array}{l}2016, \\
\text { Austrália }\end{array}$ & $\begin{array}{l}\text { How domesticity dictates behaviour in } \\
\text { the birth space: Lessons for designing } \\
\text { birth environments in institutions } \\
\text { wanting to promote a positive } \\
\text { experience of birth. }\end{array}$ & $\begin{array}{l}\text { Explorar o conceito de } \\
\text { domesticidade dentro do espaço de } \\
\text { nascimento. }\end{array}$ \\
\hline 10 & $\begin{array}{l}2010 \\
\text { Reino Unido }\end{array}$ & $\begin{array}{l}\text { Psychological factors that impact on } \\
\text { women's experiences of first-time } \\
\text { motherhood: a qualitative study of the } \\
\text { transition. }\end{array}$ & $\begin{array}{l}\text { Explorar a transição materna } \\
\text { da perspectiva das mulheres e } \\
\text { Identificar quaisquer necessidades } \\
\text { de suporte não atendidas. }\end{array}$ \\
\hline 11 & $\begin{array}{l}2017, \\
\text { Reino Unido }\end{array}$ & $\begin{array}{l}\text { Becoming an 'Amai': Meanings and } \\
\text { experiences of motherhood amongst } \\
\text { Zimbabwean women living in } \\
\text { Melbourne, Australia }\end{array}$ & $\begin{array}{l}\text { Discutir o significado da } \\
\text { experiência da maternidade sob a } \\
\text { perspectiva de mulheres migrantes } \\
\text { zimbabuenses que vivem em } \\
\text { Melbourne Austrália. }\end{array}$ \\
\hline 12 & $\begin{array}{l}1995 \\
\text { Brasil }\end{array}$ & $\begin{array}{l}\text { Vivenciando a gravidez: processos } \\
\text { e sub-processos de uma teoria } \\
\text { fundamentada nos dados. }\end{array}$ & $\begin{array}{l}\text { Explorar e compreender o período } \\
\text { da gravidez a partir da perspectiva } \\
\text { de mulheres em estado de gravidez. }\end{array}$ \\
\hline 13 & $\begin{array}{l}2014, \\
\text { Austrália }\end{array}$ & $\begin{array}{l}\text { Inside stories: Maternal representations } \\
\text { of first time mothers from pre- } \\
\text { pregnancy to early pregnancy. }\end{array}$ & $\begin{array}{l}\text { Compreender em que momento } \\
\text { são ativadas as representações } \\
\text { maternas. }\end{array}$ \\
\hline 14 & $\begin{array}{l}2015, \\
\text { Austrália }\end{array}$ & $\begin{array}{l}\text { (Re)constructing myself: the process of } \\
\text { transition to motherhood for women } \\
\text { with a disability. }\end{array}$ & $\begin{array}{l}\text { Explorar o processo de transição } \\
\text { para a maternidade da perspectiva } \\
\text { das mulheres com deficiência e as } \\
\text { relações deste para si mesma. }\end{array}$ \\
\hline 15 & $\begin{array}{l}2004, \\
\text { Irlanda }\end{array}$ & $\begin{array}{l}\text { Positive experiences of teenage } \\
\text { motherhood: a qualitative study. }\end{array}$ & $\begin{array}{l}\text { Investigar as experiências das } \\
\text { mães adolescentes. Relação com } \\
\text { o papel delas como mães e suas } \\
\text { expectativas de Futuros. }\end{array}$ \\
\hline 16 & $\begin{array}{l}2016, \\
\text { Inglaterra (Reino } \\
\text { Unido) }\end{array}$ & $\begin{array}{l}\text { Struggling with motherhood and } \\
\text { coping with fatherhood - A grounded } \\
\text { theory study among Thai teenagers. }\end{array}$ & $\begin{array}{l}\text { Obter uma compreensão mais } \\
\text { profunda das perspectivas, } \\
\text { experiências e } \\
\text { Sonhando com o fato de ser e } \\
\text { ser um pai adolescente de uma } \\
\text { perspectiva de gênero. }\end{array}$ \\
\hline 17 & $\begin{array}{l}2017 \\
\text { Brasil }\end{array}$ & $\begin{array}{l}\text { Maternidade: significados atribuídos } \\
\text { por adolescentes primíparas. }\end{array}$ & $\begin{array}{l}\text { Compreender os significados } \\
\text { atribuídos por adolescentes } \\
\text { primíparas sobre o ser mãe na } \\
\text { adolescência. }\end{array}$ \\
\hline 18 & $\begin{array}{l}2008 \\
\text { Brasil }\end{array}$ & $\begin{array}{l}\text { "Tava morta e revivi": significado de } \\
\text { maternidade para adolescentes com } \\
\text { experiência de vida nas ruas. }\end{array}$ & $\begin{array}{l}\text { Identificar os significados atribuídos } \\
\text { à maternidade por adolescentes } \\
\text { com experiência de vida nas ruas } \\
\text { que optaram por assumir o cuidado } \\
\text { dos filhos fora das ruas. }\end{array}$ \\
\hline
\end{tabular}


Quadro 1 - Caracterização dos estudos sobre o potencial transformador do gestar e parir analisados

\begin{tabular}{|c|c|c|c|}
\hline $\begin{array}{l}\mathbf{N}^{\circ} \\
\text { referência }\end{array}$ & Ano, local & Título & Objetivos \\
\hline 19 & $\begin{array}{l}2010, \\
\text { Bélgica }\end{array}$ & $\begin{array}{l}\text { Adolescent mothers' perspectives } \\
\text { regarding their own psychosocial and } \\
\text { health needs: A qualitative exploratory } \\
\text { study in Belgium. }\end{array}$ & $\begin{array}{l}\text { Olhar a gravidez precoce } \\
\text { e a paternidade como uma } \\
\text { oportunidade para ampliar nossa } \\
\text { compreensão das necessidades de } \\
\text { educação em saúde reprodutiva } \\
\text { atendidas por meninas adolescentes. }\end{array}$ \\
\hline 20 & $\begin{array}{l}2008 \\
\text { Brasil }\end{array}$ & $\begin{array}{l}\text { Representações sociais de adolescentes } \\
\text { primíparas sobre "ser mãe". }\end{array}$ & $\begin{array}{l}\text { Analisar e comparar as } \\
\text { representações sociais de } \\
\text { adolescentes primíparas, acerca } \\
\text { de "ser mãe", antes e após o } \\
\text { nascimento dos bebês. }\end{array}$ \\
\hline 21 & $\begin{array}{l}2016 \\
\text { Brasil }\end{array}$ & $\begin{array}{l}\text { Maternidade na adolescência: } \\
\text { ressignificando a vida? }\end{array}$ & $\begin{array}{l}\text { Identificar as transformações } \\
\text { oriundas da maternidade na } \\
\text { adolescência na perspectiva de } \\
\text { jovens mulheres. }\end{array}$ \\
\hline 22 & $\begin{array}{l}2004, \\
\text { Ásia, Norte e } \\
\text { América Central, } \\
\text { médio Oriente, } \\
\text { Escandinávia, } \\
\text { África do Sul }\end{array}$ & $\begin{array}{l}\text { Making meaning: women's birth } \\
\text { narratives. }\end{array}$ & $\begin{array}{l}\text { Rever o uso de narrativas de parto } \\
\text { para iluminar experiências de parto } \\
\text { para descrever as percepções das } \\
\text { mulheres sobre os benefícios, } \\
\text { combinações de histórias de } \\
\text { nascimento e significados } \\
\text { selecionados de nascimento que } \\
\text { atravessava contextos culturais. }\end{array}$ \\
\hline 23 & $\begin{array}{l}2005, \\
\text { Suécia Ocidental }\end{array}$ & $\begin{array}{l}\text { Becoming and being a teenage mother: } \\
\text { how teenage girls in south western } \\
\text { sweden view their situation. health } \\
\text { care for women international. }\end{array}$ & $\begin{array}{l}\text { Descrever as perspectivas, } \\
\text { experiências e raciocínios sobre } \\
\text { como se tornar e ser uma mãe } \\
\text { adolescente por Adolescentes } \\
\text { suecas. }\end{array}$ \\
\hline 24 & $\begin{array}{l}\text { 2014, } \\
\text { Nova Zelândia }\end{array}$ & Mood and birth experience. & $\begin{array}{l}\text { Explorar o fenômeno de humor } \\
\text { no nascimento. Usando a noção } \\
\text { heideggeriana. }\end{array}$ \\
\hline 25 & $\begin{array}{l}\text { 2010, } \\
\text { Armênia }\end{array}$ & $\begin{array}{l}\text { Giving birth: the voices of Armenian } \\
\text { women. }\end{array}$ & $\begin{array}{l}\text { Descrever as percepções } \\
\text { das mulheres armênias sobre o } \\
\text { significado de dar à luz e realizar } \\
\text { uma avaliação de resultados. Do } \\
\text { Erebuni Women's Wellness Center. }\end{array}$ \\
\hline 26 & $\begin{array}{l}2013, \\
\text { Inglaterra }\end{array}$ & A hero's tale of childbirth. & $\begin{array}{l}\text { Apresentar uma análise secundária } \\
\text { dos achados de mulheres que } \\
\text { vivenciaram uma experiência de } \\
\text { natalidade negativa e posterior } \\
\text { positiva. }\end{array}$ \\
\hline 27 & $\begin{array}{l}\text { 2016, } \\
\text { Nova Zelândia }\end{array}$ & $\begin{array}{l}\text { Midwifing the notion of a 'good' birth: } \\
\text { a philosophical analysis. }\end{array}$ & $\begin{array}{l}\text { Refletir novamente o que faz uma } \\
\text { boa experiência de nascimento de } \\
\text { maneira audivel. }\end{array}$ \\
\hline 28 & $\begin{array}{l}\text { 2011, } \\
\text { Gâmbia }\end{array}$ & $\begin{array}{l}\text { Women's experiences of pregnancy, } \\
\text { childbirth, and the postnatal period in } \\
\text { The Gambia: A qualitative study. }\end{array}$ & $\begin{array}{l}\text { Explorar qualitativamente as } \\
\text { experiências de mulheres em } \\
\text { gravidez, parto, período pós-natal e } \\
\text { sofrimento psicológico. }\end{array}$ \\
\hline 29 & $\begin{array}{l}2006, \\
\text { Brasil }\end{array}$ & $\begin{array}{l}\text { Fatores culturais que interferem nas } \\
\text { experiências das mulheres durante o } \\
\text { trabalho de parto e parto. }\end{array}$ & $\begin{array}{l}\text { Compreender os fatores que } \\
\text { interferem nas experiências vividas } \\
\text { pela parturiente. }\end{array}$ \\
\hline
\end{tabular}

Fonte: Elaboração própria. 
A análise de conteúdo temático do material selecionado para este estudo permitiu identificar conteúdos relevantes em pesquisas qualitativas, mas optou-se por apresentar a síntese em forma de imagem e realizar a discussão dos principais achados em seguida.

\section{Gestação como ponto de transformação}

Ao se perceber a gestação como ponto de transformação, identificou-se estudo que assinala o começo da transição para maternidade logo nos primeiros momentos da gestação e só estará concluída quando a mulher retomar o sentimento de controle sobre sua vida pessoal, que se dá algum tempo após o nascimento ${ }^{(10)}$.

Observou-se que a mulher inicia o sentimento de perda de controle, quando percebe que não está mais sozinha. Seu corpo e seus desejos estão sujeitos a sintomatologias típicas do primeiro trimestre de gravidez, como enjoos e indisposições, causando um impacto sobre as mudanças que estão por vir. Isso perpetua a premissa de que a maternidade não só molda a vida e a identidade da mulher, mas também perturba o seu senso de si mesma ${ }^{(11)}$.

As evidências enfatizam que o processo de mudança é associado à perda de controle da mulher, seja no aspecto físico, seja no mental, que tem início nos primeiros momentos da gestação, permanecendo durante o pós-parto, período de adaptações, em que a mulher estará em doação às necessidades do bebê, sobrepondo-as às suas. Esse processo de transição teve um impacto no autoconceito das mulheres. Em algumas mães, isso poderia ser diretamente relacionado à maturação pessoal, sendo o marco inicial de uma mudança, relatada por todas como maior responsabilidade ${ }^{(10-11)}$.

Vale ressaltar que os sintomas físicos atenuados permitem à mulher demorar um período maior para se sentir grávida, mesmo com teste de gravidez positivo. Até que o bebê manifeste-se em sua individualidade, trazendo a mulher para a conexão com a vida que está se desenvolvendo em seu ventre, essa consciência faz com que elas iniciem um processo mental de pensar sobre a gravidez como um tempo de sua vida, o que provoca uma avaliação e/ou comparação com outros momentos do seu viver ${ }^{(12)}$.

De acordo com o prisma da psicanálise, complementando o que foi dito, é durante a gestação que a representação mãe e filho será ativada. Contudo, nos casos de gestações planejadas, o período de pré-gravidez pode ser entendido como o momento em que a mulher está ativamente reformulando a imagem de si mesma como mulher e construindo uma nova imagem de si mesma como mãe $\mathrm{e}^{(13)}$.

Tal reformulação, segundo as falas contidas no estudo, que discorrem sobre o momento em que são ativadas as representações maternas, em que todas as mulheres participantes de pesquisa realizada na Austrália definiram a maternidade como um momento de crescimento pessoal, definição de personalidade e desenvolvimento que trouxe um sentimento de pertencimento, propósito, autoestima, feminilidade e autoconfiança ${ }^{(14)}$.

Em gestantes adolescentes, esse processo de ressignificação é potencializado. Em sete artigos sobre gravidez na adolescência, identificados no presente estudo, as jovens mães discorriam sobre sua maior responsabilidade e crescimento pessoal, atrelados à definição de personalidade e reformulação da autoimagem. Isso sugere que a gravidez na adolescência nem sempre é algo imprevisível, e, na maioria das vezes, torna-se um fator estabilizador em suas vidas ${ }^{(15-21)}$.

Assumir a gravidez para a sociedade é colocar a mulher em uma posição de mudança de identidade social, trazendo a possibilidade de reformulação em todos os âmbitos da sua vida ${ }^{(13)}$. Esse fato é confirmado por mães adolescentes em situação de vulnerabilidade socioeconômica, que encontraram, na maternidade, a ressignificação do sentido existencial, antes fragilizado, redefinindo-o no papel de progenitora, provedora e responsável ${ }^{(18-21)}$. 
Figura 2 - Gestação, ponto de transformação

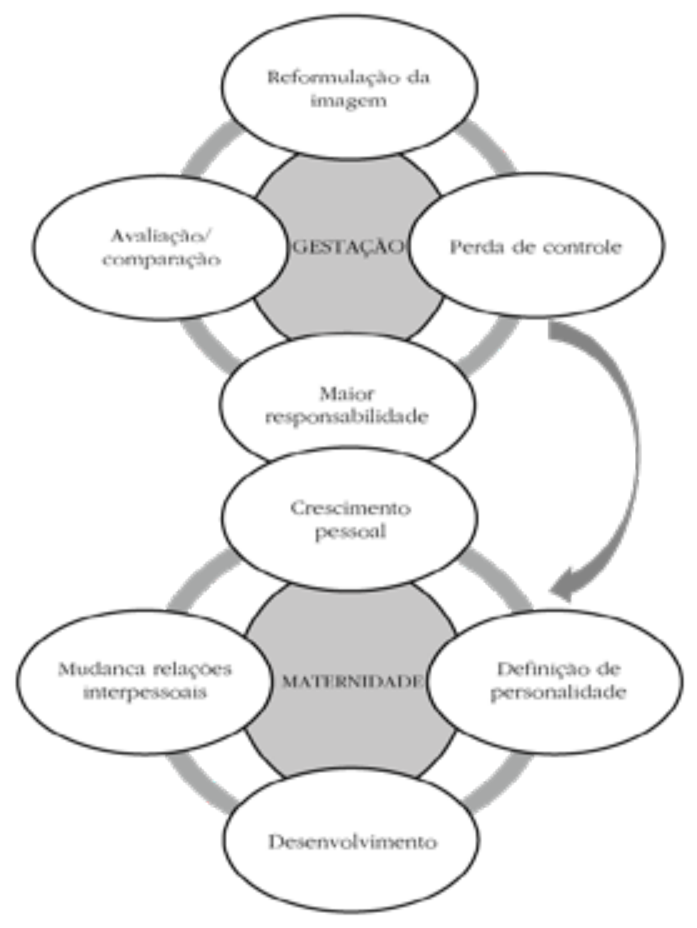

Fonte: Elaboração própria.

Na Figura 2, elaborada com base na análise de conteúdo temático extraída dos estudos qualitativos selecionados, foi possível estabelecer um paralelo gráfico, por meio de fluxograma, da relação gestação e maternidade (representadas pelos dois círculos cinzas principais), assim como seus consequentes pontos de transformação ocorridos e relatados pelas mulheres (representados pelos círculos brancos). Por meio dessa representação gráfica, fica evidente, de forma positiva, que a maternidade inseriu essas mulheres na sociedade da qual sentiam-se excluídas, pois tinham reconfigurado suas relações interpessoais e não estavam mais dispostas a aceitar o indeferimento dos outros ${ }^{(21)}$.

Desse modo, a maternidade é explicada como a experiência mais profunda que se pode ter como mulher, e não deve ser comparada a nenhuma outra vivência ${ }^{(22)}$, mesmo se tratando de um misto entre uma bela vista e uma verdadeira selvageria ${ }^{(11)}$.

\section{Influência do meio em que vivem}

O apoio social, identificado como fator capaz de influenciar a maneira pela qual a transição era experimentada, aliado à convivência com outras mães, o apoio do parceiro, a presença da própria mãe, assim como as informações compartilhadas por grupos de pré-natal e profissionais de saúde, encontrava-se presente, como guia para a construção dessa nova personalidade ${ }^{(12)}$. Vale enfatizar que a rede de relacionamentos é dinâmica, visto que envolve não apenas o ambiente físico, mas também um conjunto de fatores, entre os quais se destacam o ambiente familiar, cultural, social, econômico, histórico, político, entre outros. Esses fatores são capazes de moldar as diferentes percepções, bem como o tipo de enfrentamento das situações que se descortinam a cada fase da gestação e parto. As mulheres trazem consigo sentimentos de vulnerabilidade que poderiam ser (re)significados ao serem compartilhados e acolhidos por outras mulheres que enfrentam o mesmo ${ }^{(10)}$.

Mulheres imigrantes da África para Austrália afirmaram que criar filhos no Zimbábue era muito fácil, pois todos eram família e ajudariam a cuidar da criança. No entanto, na Austrália, era uma tarefa difícil para um casal, exatamente pela falta desse apoio ${ }^{(11)}$. 
Para gestantes adolescentes, o apoio da própria mãe é necessário como suporte emocional e de orientação para o desenvolvimento de habilidades de cuidado ainda não exploradas por elas. Além disso, o suporte familiar era indispensável para prover as condições financeiras e estruturais necessárias nesse caso em específico ${ }^{(16-17,23)}$.

Os profissionais de saúde possuem um desafio ao lidarem com essa faixa etária, por se tratar de uma consciência pessoal ainda fragilizada. A expressão de suas necessidades e anseios de forma contextualizada é dificultada nessa fase ${ }^{(16,23)}$. Ao mesmo tempo, essas jovens necessitam de uma atenção diferenciada para melhor adaptarem-se ao processo de mudança de vida ${ }^{(17)}$.
As informações fornecidas por profissionais podem estar excessivamente relacionadas a questões biológicas de cunho curativo, deixando em aberto as necessidades de esclarecimento de cunho psicossocial ${ }^{(10,12)}$. Faz-se necessária a valorização das percepções da família e seus contextos culturais e singulares ${ }^{(11)}$.

Esse aspecto fica evidenciado, quando se observam os vários fatores que afetam diretamente a mulher. Desse modo, torna-se importante para o profissional de saúde compreender os elementos extrínsecos que influenciam diretamente a mulher nesse processo, como se pode observar na Figura 3.

Figura 3 - Influência do meio em que vivem as mulheres

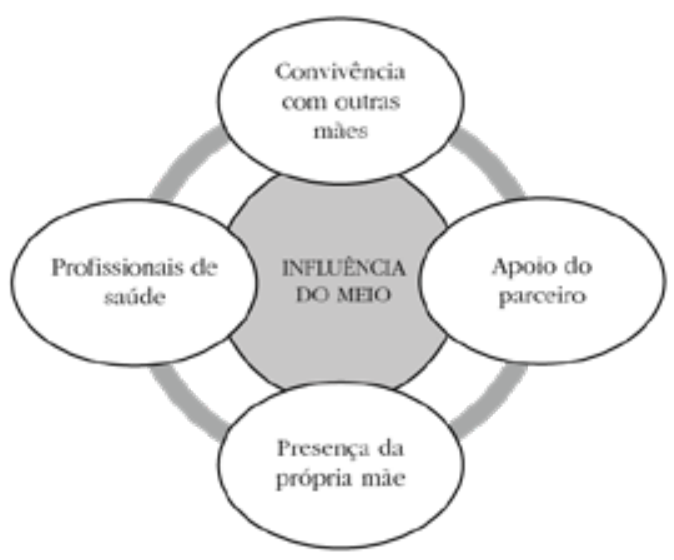

Fonte: Elaboração própria.

A Figura 3 demonstra graficamente os principais elementos elencados nos estudos selecionados, no que diz respeito à influência que podem exercer sobre as mulheres e seus familiares. Assim, os profissionais de saúde que lidam diretamente com a gestação e o parto, em geral médicos e enfermeiros, necessitam conhecer as teorias psicológicas no tocante ao conceito de representação materna, para melhorar a prática da obstetrícia e facilitar a visão ampliada para a mulher sobre os aspectos psicológicos da gravidez, podendo promover uma experiência rica e satisfatória ${ }^{(13)}$.

\section{Parto como transição}

Ao analisar a vivência do parto por diferentes aspectos, as evidências qualitativas apontaram-no como um portal de passagem, um limiar, uma transição, uma transferência. Nesse transcurso, estudo demonstrou que, por meio da teoria do filósofo alemão Heidegger, profissionais, parturientes e acompanhantes emergiram uma perspectiva de sintonização do indivíduo com o humor do ambiente, que, por sua vez, compõem-se do humor daqueles que compartilham o mesmo ambiente. Esta sintonização sutil está não apenas no campo da subjetividade, como também na comunicação compartilhada, capaz de influenciar desde os níveis de percepção e entrega até as experiências que o momento proporciona ${ }^{(24)}$.

No tocante à presença ou ausência de reverência ao momento do parto por parte dos profissionais, é importante enfatizar que deveriam 
compreendê-lo como algo significativo e sagrado, para além de um evento biológico. Isso possibilitaria a manutenção da sintonia de alegria do momento, para que a parturiente estivesse tranquilamente entregue. Dessa forma, sugere-se que o nascimento é mais do que apenas tirar o bebê saudável; aponta para algo constitutivo do parto como experiência única ${ }^{(24)}$. Aquelas que dizem não ter encontrado a emoção prometida, acreditam que o parto possa ter sido excessivamente romantizado. Exaltam ainda que, ser informada quanto à existência da dor não as tornou preparadas para o quão profunda esta dor realmente é. Assim, encontravam-se cansadas demais para exacerbarem qualquer sentimento sublime ${ }^{(22,25)}$.

O parto que deixou traumas é definido como o que ocorreu sem conexão com a equipe, em que existiam duas ou mais pessoas e não se encontrou a possibilidade de vinculação com nenhuma delas. Dessa forma, a equipe era vista como distante e insensível ao momento. O mesmo aconteceu também em partos laboriosos, nos quais foi necessária a instrumentação e não houve tempo para que a mulher (re)significasse o evento ${ }^{(26)}$.

Assim, o trauma do parto, diretamente associado à desconexão da mulher com o seu protagonismo durante a parturição, acarretou dificuldades para a iniciação da maternidade pós-hospitalar, a difícil aceitação da criança e a presença de uma autocrítica que dizia ser essa mulher disfuncional, por não ter conseguido ser ativa em seu rito de iniciação como mãe. Seus bebês eram saudáveis, mas havia-lhes sido negado o senso de transformação na maternidade e foi bloqueada a entrada no reino da maternidade ${ }^{(26)}$. Essas mulheres voltavam para casa sentindo-se fortes e capazes de exercer a maternidade, por terem transpassado o rito de iniciação de forma gloriosa e estavam em celebração. O parto também qualificou seus relacionamentos conjugais, bem como as redes sociais de apoio ${ }^{(22,26)}$. Muitas mulheres acabam por aprender que apresentam muito mais pontos fortes do que pensavam ter. O parto trouxe sintonia com seu corpo e conhecimento sobre sua capacidade mental e força ${ }^{(26)}$.

Posto isso, serviços de parto devem compreender que um nascimento positivo vai muito além de uma assistência bem feita e uma criança saudável. Trata-se de envolver-se completamente com a natureza desconhecida e incognoscível do parto. Estes são como pedaços que explodem em múltiplas camadas de sentido e significado e tornam-se parte da nova mulher que se construiu por todo esse processo ${ }^{(26)}$. A sensação de domínio adquirido ao gerenciar os desafios do trabalho de parto, descreve um sentido de elevação e realização ${ }^{(22)}$. Esse aspecto é mostrado na Figura 4, que representa os elementos que potencializam o parto como transição do que a mulher era para a transformação em um ser ressignificado.

Figura 4 - Parto como transição

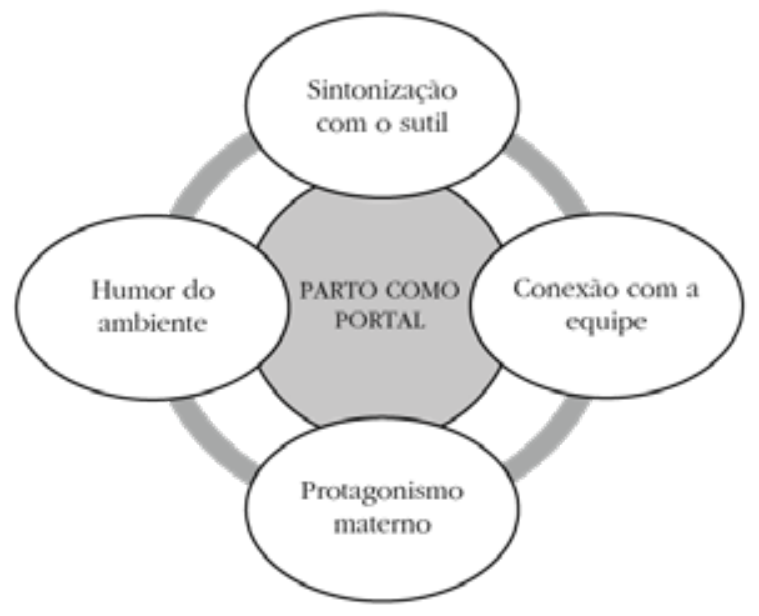

Fonte: Elaboração própria. 
Nesse sentido, o ambiente destaca-se como elemento promotor dessa transformação. O senso de lugar, de cultura e de pertencimento fazem parte do nascimento. Por isso, o ambiente físico possui grande influência na resposta da mulher. Em espaços desprovidos das características comumente associadas a um espaço doméstico, a maioria das mulheres atuou e interagiu com o meio de forma passiva e rapidamente se tornaram pacientes. Entre as seis participantes do estudo analisado, apenas uma conseguiu reformular o ambiente onde estava internada, a ponto de interagir livremente, enquanto as outras apresentaram dificuldade para apossar-se dele, estando visivelmente limitadas a comandos da equipe, e preferencialmente presas à cama, esvaindo a capacidade de reger suas próprias histórias de parto, perdendo o enraizamento psicológico ${ }^{(3)}$.

A análise mais aprofundada, que considera o sutil do parto, permite afirmar-se que não se pode simplesmente criar uma nova unidade de parto e assumir que oferecerá uma boa experiência de nascimento, pois a experiência é muito mais abrangente ${ }^{(27)}$. Centralizar a capacidade de oferecer um bom nascimento, no tocante ao profissional, ao local ou à própria mulher e/ou acompanhante, é um simulacro, fadando o evento ao enfraquecimento por desconexão do todo $^{(3,27)}$. O quádruplo da vida apresenta-se no momento do parto como o local, o momento, o profano e o sagrado em uma sintonia absoluta de interdependência e sentido que existe em todos os partos, mas precisa de condições adequadas para ser acessada; sentir-se confiante no "eu" é parte do mistério ${ }^{(27)}$.

Em países onde a cultura segue arraigada, como em Gâmbia, na África subsaariana, a presença do pai durante o parto, assim como a ambiência e participação no apoio à gestação, ainda se apresentam como comportamentos de difícil aceitação, sendo um ponto que predispõe à não satisfação durante o trabalho de parto e à grande angústia durante a gestação ${ }^{(28)}$. Já as mulheres armênias, sentiam-se bem com a não aceitação do companheiro durante o parto, no entanto frisavam a existência de apoio e suporte emocional e físico vindo da equipe, o que supria a necessidade de amparo e permitia-lhes uma vivência satisfatória ${ }^{(25)}$. A prática do cuidado cultural na assistência à mulher mostrou como é importante a comunicação e o respeito às suas crenças e valores no momento do trabalho de parto e parto $^{(29)}$.

Como limitação para esta pesquisa observou-se o número ainda reduzido de estudos relacionados ao fator psicossocial da gestação e do parto. As publicações, em sua maioria, relacionavam-se ao desenvolvimento biofisiológico desses processos. Este fato preocupa e demonstra a necessidade de um olhar mais ampliado em relação ao momento da gravidez e do parto, como fenômenos amplos e complexos, a fim de envolver os sujeitos implicados nesse processo com vistas a agregar qualidade à atenção obstétrica, desvelando uma realidade que transcende sua dimensão biologicista.

\section{Conclusão}

Pôde-se considerar, ancorando-se na presente metassíntese, que o impacto da gestação como evento-chave desencadeia, de forma intrínseca, o potencial transformador, possibilitando a reformulação da mulher em vários âmbitos de sua vida. No entanto, ele necessita ser fomentado pelo meio, devendo os profissionais de saúde tornarem-se responsáveis por compreender e possibilitar a intermediação adequada para tal, em todas as fases do processo de gestação, parto e puerpério.

O estudo proporcionou a produção de evidências relativas à temática e aos delineamentos investigados nas pesquisas qualitativas que envolviam o processo transformador do gestar e do parir na vida de mulheres e de suas famílias, para colaborar na qualificação das práticas profissionais. Para tanto, a literatura tornou-se fonte de dados e disparador de reflexões. Isso ganha potência, tendo em vista ser um desafio atual da área da saúde a utilização de resultados de estudos qualitativos para embasar a prática clínica. 


\section{Colaborações:}

1 - concepção, projeto, análise e interpretação dos dados: Zayonaria Magalhães Mendonça Mota e Antonio Rodrigues Ferreira Júnior;

2 - redação do artigo e revisão crítica relevante do conteúdo intelectual: Zayonaria Magalhães Mendonça Mota, Saiwori de Jesus Silva Bezerra dos Anjos, Alisson Salatiek Ferreira de Freitas e Antonio Rodrigues Ferreira Júnior;

3 - aprovação final da versão a ser publicada: Zayonaria Magalhães Mendonça Mota, Saiwori de Jesus Silva Bezerra dos Anjos, Alisson Salatiek Ferreira de Freitas e Antonio Rodrigues Ferreira Júnior.

\section{Referências}

1. Walsh F. The concept of family resilience: crisis and challenge. Fam Process. 1996 Sep;35(3):261-81.

2. Weiner E. Onde nascem os gêmeos. 35a ed. Rio de Janeiro: DarkSide Book; 2016.

3. Mondy T, Fenwick J, Leap N, Foureur M. How domesticity dictates behaviour in the birth space: Lessons for designing birth environments in institutions wanting to promote a positive experience of birth. Midwifery. 2016;43:37-47.

4. Pedreira M, Leal I. Terceiro trimestre de gravidez: expectativas e emoções sobre o parto. Psic Saúde Doenças [Internet]. 2015 set [cited 2017 Nov 24];16(2):254-66. Available from: http://www.scielo. mec.pt/scielo.php?script=s-ci_arttext\&pid $=$ S164500862015000200010\&lng=pt.

5. Luhmann $M$, Hofmann $W$, Eid $M$, Lucas RE. Subjective well-being and adaptation to life events: a meta-analysis. J Pers Soc Psychol. 2012 Mar;102(3):592-615.

6. Arrais AR, Araújo TCCF. Pré-natal psicológico: perspectivas para atuação do psicólogo em saúde materna no Brasil. Rev SBPH [Internet]. 2016 [cited 2017 Nov 23];19(1):103-16. Available from: http://pepsic.bvsalud.org/scielo.php?script=sci_ arttext\&pid=S151608582016000100007\&lng=pt.

7. Ragagnin M, Marchiori M, Diaz C, Nicolli T, Pereira S, Silva $\mathrm{L}$. The approach of the nursing team about the humanized childbirth during the prenatal: a narrative review. Rev pesqui cuid fundam (Online). 2017 [cited 2017 Dez 20];9(4):1177-82. Available from: http://www.seer.unirio.br/index. php/cuidadofundamental/-article/view/6394

8. Reis TLR, Padoin SMM, Toebe TRP, Paula CC, Quadros JS. Autonomia feminina no processo de parto e nascimento: revisão integrativa da literatura. Rev Gaúcha Enferm [Internet]. 2017 [cited 2017 Dez 20];38(1):e64677. Available from: http://www. scielo.br/scielo.php?script=sci_arttext\&pid=S1983$14472017000100503 \& \operatorname{lng}=$ en.

9. Oliveira A, Trancoso A, Bastos J, Canuto TL. Metassíntese apontamentos para sistematização de revisões amplas e crítica interna à produção científica. Atas CIAIQ2015. 2015;1:147-52.

10. Darvill R, Skirton H, Farrand P. Psychological factors that impact on women's experiences of first-time motherhood: a qualitative study of the transition. Midwifery. 2010;26(3):357-66.

11. Benza S, Liamputtong P. Becoming an 'Amai': Meanings and experiences of motherhood amongst Zimbabwean women living in Melbourne, Australia. Midwifery. 2017 Feb;45:72-8. doi: 10.1016/j.midw.2016.12.011.

12. Marcon SS. Vivenciando a gravidez: processos e sub-processos de uma teoria fundamentada nos dados. Rev latino-am enfermagem [Internet]. 1995 [cited 2017 Dez 20];3(2):165-79. Available from: http://www.scielo.br/scielo.php?script=sci_ arttext\&pid=S010411691995000200012\&lng=en.

13. Hopkins J, Clarke D, Cross W. Inside stories: Maternal representations of first time mothers from pre-pregnancy to early pregnancy. Women and Birth. 2014; 27(1):26-30

14. Lawler D, Begley C, Lalor J. (Re)constructing Myself: the process of transition to motherhood for women with a disability. J Adv Nurs. 2015 Jul;71(7):1672-83. doi: 10.1111/jan.12635.

15. Seamark CJ, Lings P. Positive experiences of teenage motherhood: a qualitative study. Br J Gen Pract. 2004 Nov;54(508):813-8.

16. Sriyasak A, Almqvist Al, Sridawruang C, Neamsakul W, Häggström-Nordin E. Struggling with motherhood and coping with fatherhood A grounded theory study among Thai teenagers. Midwifery. 2016 Nov;42:1-9. doi: 10.1016/j. midw.2016.09.005. 
17. Lima FBN, Lira GG, Melo RA, Mola R, Fernandes FECV. Maternidade: significados atribuídos por adolescentes primíparas. Rev enferm UFPE [on line]. 2017;11(3):1163-70. Available from: https:// periodicos.ufpe.br/rev-istas/revistaenfermagem/ article/viewFile/13491/16212

18. Gontijo DT, Medeiros M. "Tava morta e revivi": significado de maternidade para adolescentes com experiência de vida nas ruas. Cad saúde pública [Internet]. 2008 [cited 2017 Dez 20];24(2):469-72. Available from: http://www.scielo.br/scielo.php?script=sci_ arttext\&pid=S0102311X2008000200026\&lng=en.

19. Aujoulat I, Libion F, Berrewaerts J, NoirhommeRenard F, Deccache A. Adolescent mothers' perspectives regarding their own psychosocial and health needs: A qualitative exploratory study in Belgium. Patient Educ Couns. 2010;81(3):448-53.

20. König AB, Fonseca AD, Gomes VLO. Representações sociais de adolescentes primíparas sobre "ser mãe”. Rev eletrônica enferm [Internet]. 2008 [cited 2017 Dez 18];10(2):405-13. Available from: http:// repositorio.furg.br/bitstream/handle/1/4554/ representa $\%$ C3\%A7oes\%20sociais $\% 20 \mathrm{de} \% 20$ adolescentes $\% 20$ primiparas.pdf?sequence $=1$

21. Zanchi M, Kerber NPC, Biondi HS, Silva MR, Gonçalves CV. Maternidade na adolescência: ressignificando a vida? J Hum Growth Dev. 2016;26(2):199-204.

22. Callister LC. Making meaning: women's birth narratives. J Obstet Gynecol Neonatal Nurs. 2004 Jul-Aug;33(4):508-18.
23. Wahn EH, Nissen E, Ahlberg BM. Becoming and being a teenage mother: how teenage girls in south western Sweden view their situation. Health Care Women Int. 2005 Aug;26(7):591-603.

24. Crowther S, Smythe L, Spence D. Mood and birth experience. Women birth. 2014;27(1):21-5.

25. Amoros ZU, Callister LC, Sarkisyan K. Giving birth: the voices of Armenian women. Int Nurs Rev. 2010 Mar;57(1):135-41. doi: 10.1111/j.1466-7657.2009.00775.x.

26. Thomson G, Downe S. A hero's tale of childbirth. Midwifery. 2013;29(7):765-71.

27. Smythe E, Hunter M, Gunn J, Crowther S, Couper $\mathrm{Jm}$, Wilson S. Midwifing the notion of a 'good' birth: a philosophical analysis. Midwifery. 2016 Jun;37:25-31. doi: 10.1016/j.midw.2016.03.012.

28. Sawyer A, Ayers S, Smith H, Sidibeh L, Nyan O, Dale J. Women's experiences of pregnancy, childbirth, and the postnatal period in The Gambia: A qualitative study. Br J Health Psychol. 2011 Sep;16(3):528-41. doi: 10.1348/135910710X528710.

29. Bezerra MGA, Cardoso MVLML. Fatores culturais que interferem nas experiências das mulheres durante o trabalho de parto e parto. Rev Latino-am Enfermagem. 2006 maio-jun;14(3):414-21.

Recebido: 1 de outubro de 2018 Aprovado: 2 de setembro de 2019

Publicado: 23 de janeiro de 2020

A Revista Baiana de Enfermagem utiliza a Licença Creative Commons - Atribuição-NãoComercial 4.0 Internacional. https://creativecommons.org/licenses/by-nc/4.0/

Este artigo é de acesso aberto distribuído sob os termos da Licença Creative Commons (CC BY-NC). Esta licença permite que outros remixem, adaptem e criem a partir do seu trabalho para fins não comerciais. Embora os novos trabalhos tenham de lhe atribuir o devido crédito e não possam ser usados para fins comerciais, os usuários não têm de licenciar esses trabalhos derivados sob os mesmos termos. 